\title{
Macrothink

\section{Measuring Moroccan English Department University Students' (Meta) Cognitive Awareness and Usage of Reading Strategies}

\author{
Mohammed Msaddek (Corresponding author) \\ Department of English Studies, Faculty of Letters and Human Sciences- Mohammedia, \\ Hassan II University, Casablanca, Morocco \\ E-mail: msadek60@gmail.com
}

Received: May 24, 2020 Accepted: June 28, 2020 Published: June 30, 2020

doi:10.5296/ijld.v10i2.17281 URL: https://doi.org/10.5296/ijld.v10i2.17281

\begin{abstract}
Grounded in an exploratory research design, the current study is centrally aimed at gauging the Moroccan English department learners' awareness and use of cognitive and metacognitive reading strategies (RSs). It seeks to determine the extent to which EFL learners are (meta) cognitively conscious of the use of text-based strategies. To put a bright spotlight on this issue and disclose EFL learners' dynamic potential pertaining to metacognitive strategy knowledge, a sample of sixty-three (63) EFL learners majoring in English Studies (first-semester) was targeted. The obtained data were gathered by means of the retrospective questionnaire (RQ) and the reading comprehension texts (e.g., narrative, expository). The overall findings manifestly show that Moroccan EFL learners' (meta) cognitive strategy awareness and usage are characterized by insufficiency. Thus, a range of implied suggestions related to the EFL learners' reading strategy consciousness and use in academic textual reading are put forward and some encountered research limitations are stated.
\end{abstract}

Keywords: Information processing, metacognition, reading strategies, strategy awareness, strategy usage

\section{Introduction}

The pivotal significance of metacognition in perceived reading strategy awareness and use has been underscored by many researchers (Mokhtari \& Reichard, 2002; Taraban, Kerr, \& Rynearson, 2004; Lawrence, 2007; Zhang \& Wu, 2009; Hong-Nam, 2014; Boyraz \& Altinsoy, 2017). Indeed, as a key constituent assuring the conduct of an efficiency-driven, competent type of academic reading, especially at the university level, metacognitive knowledge of 
reading strategies (RSs) is a requirement that should be accorded core importance in the field of academia. Reading strategy awareness can serve as a foundational platform for effective, concerted usage of strategies in textual analysis conducted by university students. Thus, knowing 'what', 'how' and 'when' to use reading strategies (RSs) is a prerequisite for the improvement of their reading potential.

A corpus of pertinent research studies (Mokhtari \& Sheory, 2002; Mokhtari \& Reichard, 2002; Zhang \& Wu, 2009) addressed the learners' awareness of reading strategies (RSs). For instance, using a 'self-report' measure called MARSI (Metacognitive Awareness of Reading Strategies Inventory), Mokhtari and Reichard (2002) came to the explicit conclusion that 'global' and 'problem-solving' strategies are frequently tapped by skilled readers during the reading act. Another study (Mokhtari \& Sheory, 2002) revealed that competent readers invariably resort to cognitive and metacognitive RSs compared to their counterparts, 'incompetent' learners, who underutilize these strategies. This study indicates a sturdy association between higher reading capability and strategy use. Comparably, targeting EFL high school students, Zhang and Wu (2009) declared that the high-proficient group significantly relies on global and problem-solving strategies compared to the intermediate and low-proficient groups.

Yet, given the potential findings reported by these studies which contribute to the existing research body, it is remarkable that the exploration of EFL university students' reading strategy awareness and use is still worthy of further, deeper scrutiny. In this regard, the basic premise that learners consciously or unconsciously use cognitive and metacognitive RSs has not been researched and elaborated upon thus far, especially within the Moroccan academic setting. In other terms, it can be posited that learners not only make use of a series of RSs automatically without being aware of their nature, but they can also utilize some strategies consciously. This postulate is to be delved into in the present study with a view to unveiling at length the Moroccan EFL university learners' conceived awareness and usage of cognitive and metacognitive RSs.

\section{Literature Review}

\subsection{Information Processing}

The concept of information processing refers to the act of processing, analyzing, synthesizing and summarizing the information with the main goal of achieving comprehension. In the past decades, many researchers (e.g., Mayer, 1996; Schneider \& Pressley, 1997) considered the use of effective strategies as efficient information processing. This attested fact reflects that, in attempting to process the ideas, concepts and information contained in a given text, readers make use of a wide range of strategies that are deemed an effective medium of gaining knowledge and understanding the included meaning.

As noted by many academic scholars (e.g., Solso, 1979; Piccinini \& Scarantino, 2010; McFarland, 2017), information processing is correlated with cognition. For instance, the act of comprehending and assimilating the information included in a particular text entails the implementation of a wide variety of cognitive processes, skills and strategies. This shows that diverse kinds of information can be processed by learners in a multitude of ways such as 
"encoding, recoding, or decoding it; comparing or combining it with other information, storing it in memory or retrieving it from memory, bringing it into or out of focal attention or conscious awareness, and so on" (Flavell, et al., 1993, p. 8). In view of this, the ideas, statements and standpoints that are reflected in typical written discourse can be comprehended by learners either in a controlled or automatic way. Within this set framework, the information processing approach encompasses two major types of content processing which are automatic processing and controlled processing.

\subsubsection{Automatic Processing}

Automatic processing is conceived of as the processes that require little mental effort and attention from learners. In essence, automatic information processing, in Sternberg's (1984) words, is "preconscious and is thus not under the voluntary direction of the individual" (p.173). That is, this kind of processing is frequently implemented by proficient learners in an unconscious way as they tend to allocate only a minimal amount of attention and cognitive capabilities to the process of text reading. In this regard, automatic processes "are performed in parallel, and are essentially unaffected by capacity constraints" (Wood, 1983). For example, predicting, inferring the meaning of words via depending on the context and focusing on the relevant ideas and key concepts can be deemed automatic processes that are made use of by learners in order to construct the text meaning. Therefore, it can be declared that automatic processing can be developed by learners as a result of being exposed to dealing with a wide range of cognitive tasks.

Evidently, the development of automatic processes by the learners is what LaBerge and Samuels (1974) referred to as automaticity. The latter can be defined as the ultimate extent to which readers, as potential learners, conduct the assigned task with a minimal degree of awareness and self-monitoring. For instance, skilled readers, in processing a particular written text, can identify the meaning of some basic terminologies and sentences in a swift manner, and thus reach an effective understanding. In this perspective, Walczyk (2000) confirms that automaticity develops with practice for activities that are sufficiently routinized (p.557). This reveals that, once readers constantly or regularly analyze many different texts, they can make sense of the ideas and views incorporated in the text so readily and effectively.

Many leading educational theorists have highlighted the great importance of automatic processes (e.g., LaBerge \& Samuels, 1974; Shiffrin \& Schneider, 1977; Hartlage, et al., 1993; Schneider \& Chein, 2003; Lifshitz, et al., 2013). This type of processing actually plays an essential part in allowing EFL learners to regularly apply some effective strategies to diverse types of written discourse.

\subsubsection{Controlled Processing}

Controlled processing, on the other hand, denotes the major processes that are characterized as "slow, fine-grained, deliberative (explicit/declarative learning), and accessible to conscious awareness" (Corr, 2010, p. 380). In contrast to automatic processing, this type of information processing, which requires a highly substantial amount of cognitive effort, is performed by student-readers in a conscious, planned and controlled way. It entails not only adequate 
attention and sufficient time, but it also implies the use of some efficient strategies and processes, especially when it comes to understanding and elaborating on the textual meaning. In effect, EFL readers, as active participants in the operation of information processing, are expected to use some 'controlled processes' such as setting goals, activating background knowledge, monitoring comprehension and recalling the main ideas. These, and perhaps other strategies, entail concentration and 'attentional' effort on the part of the learner.

More explicitly, to cope with more difficult and unfamiliar cognitive tasks (e.g., text reading) requires controlled processing. This reflects the underlying premise that learners have to exert their cognitive efforts and use their mental capacities with a view to comprehending the most important facts, ideas and concepts. Basically, in an attempt to further explain this kind of information processing, which involves 'controlled' steps, Hartlage, et al. (1993) set forth some 'definitional' characteristics that apparently characterize controlled processes. They (a) [these processes] require attention and thereby take place serially, inhibit other pathways and are influenced by cognitive capacity limitations, (b) their efficiency improves with practice and (c) they can be used to cause learning (Hartlage, et al., 1993, p. 248).

In fact, both automatic and controlled processing can prove to be of critical significance in the process of undertaking a broad variety of cognitive tasks (e.g., textual reading). Any cognitive endeavour necessitates, at times, the use of both these kinds of processing. Therefore, it is assumed that their intimate interconnectedness mainly resides in the fact that some controlled processes can convert to automatic ones. This stated postulate is strongly confirmed by some researchers (Shiffrin \& Schneider, 1977; Schneider \& Chein, 2003; Levesque, Copeland, \& Sutcliffe, 2008) who maintain that controlled processes become automatic with practice, thus conserving mental effort. Generally, it can be claimed that both these two types of processes occupy a great part in information analysis and meaning synthesis.

\subsection{Metacognition and Academic Reading}

Metacognition was first introduced to the domain of cognitive and educational psychology by Flavell (1971) who placed a great emphasis on the study of human memory for understanding the inner workings and basal processes involved in thinking. Premised on the foundational theory of cognition, metacognition basically denotes "one's knowledge concerning one's own cognitive processes and products or anything related to them, e.g., the learning relevant properties of information or data" (Flavell, 1976). To illustrate, metacognition, as an effective way of directing one's cognitive efforts towards the execution of academic learning tasks, is the capability of the learner to think critically and rationally about the cognitive processes that are involved in the reading act. In effect, metacognition involves a certain measure of self-direction, self-regulation and critical thinking in performing the cognitive activity of reading.

According to Hill and Hannafin (1997), metacognitive knowledge refers to an awareness of one's cognitive processes. It plays an indispensable role in enabling learners to conduct the reading process in an efficient way. In this regard, as a cognitive process, reading is assumed to entail the readers' knowledge of their mental and thinking capabilities, the nature of the assigned task and the strategies that should be utilized in an attempt to fully digest the text 
meaning. This type of knowledge can be acquired by learners through exposing themselves to the process of critically reading a series of written discourse on a regular, ongoing basis. More explicitly, being aware of one's reading abilities, the text difficulty/easiness and the reading strategies (RSs) (e.g., predicting, inferring, monitoring, self-questioning, evaluating) can be a facilitating factor for undertaking the reading process and synthesizing the content in a proper way. In fact, the development of metacognitive knowledge is a basic foundation upon which readers depend to trace the path that they can follow in their reading of the text, and thereby improving their performance at the level of comprehension and meaning analysis.

It is crucial to state that metacognitive knowledge can be an important medium for learners to perform successful and efficient textual reading. Therefore, this kind of knowledge plays an essential role in making the process of comprehending the written discourse more meaningful. In essence, as has been suggested by prior research, metacognitive knowledge and textual reading are strongly interrelated variables (Carnoldi, 1990; Pei, 2014; Boyraz \& Altinsoy, 2017).

\section{3 ( Meta) cognitive Reading Strategies}

Reading strategies (RSs) can be grouped into two major clusters: cognitive and metacognitive strategies. Cognitive strategies (CSs) are made use of with the main purpose of understanding the input information. Granted this basic premise, CSs are implemented by the learners to make complete sense of the presented textual content. They are, in essence, "consciously controlled mechanisms the reader uses to organize and interpret the text" (Vellutino, 2003, p. 66). In attempting to comprehend a given text, readers suitably apply some CSs (e.g., predicting, inferring) which are of paramount significance for the process of constructing the meaning in a proper, efficacious way. In this sense, it can be claimed that the main rationale behind the use of cognitively-oriented strategies is the practical analysis, processing and synthesis of the ideas and views that are stated within the frame of written text.

As to metacognitive strategies (MSs), they include the aspect of the learners' awareness of their strategy use, (i.e. conscious control and regulation of adequate strategy use in various learning situations (Takač, 2008, p.53). To illustrate, in using this type of strategies, learners can be aware of their cognitive capabilities and what the task requires from them so as to achieve major progress at the level of content understanding. Further, they can also intentionally regulate and control the process of learning by opting for the appropriate steps in carefully thinking about the way they are tackling the task and reasonably reflecting on their comprehension of the meaning. In fact, if CSs are primarily used by learners to gain understanding of the content, MSs, on the other hand, "are necessary to understand how the task has been performed" (Schraw, 1998).

Thus, it can be assumed that executing reading strategies (RSs), especially the metacognitive ones, in dealing with diverse tasks of learning implies methodical as well as critical thinking on the part of learners. These strategies, in addition to contributing to the regulation of the learning process, constitute a pivotal basis upon which learners can depend in effectively analyzing and processing information. Indeed, planning, monitoring and evaluating remain the foundational strategies that are entirely metacognitive in essence. Accordingly, this study is a potential 
endeavor to measure Moroccan EFL university learners' reading strategy awareness and usage with regard to metacognition.

\section{Research Objectives and Research Questions}

The present study tends to gauge Moroccan EFL Learners' awareness and usage of (meta) cognitive reading strategies (RSs). It is intended for the identification of the extent to which learners' strategy awareness correlates with strategy usage in academic textual reading. In this respect, two major instruments such as retrospective questionnaire and reading comprehension texts (narrative and expository) were tapped for the achievement of the objectives underpinning the research study under focus. Therefore, two prime research questions have been structured:

a- To what extent are Moroccan EFL university students conscious of cognitive and metacognitive reading strategies (RSs)?

b- To what extent do Moroccan EFL university students use cognitive and metacognitive reading strategies (RSs) while processing academic texts?

\section{Research Hypotheses}

Taking critical account of the above-stated research questions, two main hypotheses have been formulated for the conduct of a comprehensive investigation.

1- Moroccan EFL university students are insufficiently aware of cognitive and metacognitive reading strategies (RSs).

2- Moroccan EFL university students insufficiently use cognitive and metacognitive reading strategies (RSs) while processing academic texts.

\section{Method}

\subsection{Participants}

A group of sixty-three (63) Moroccan university students of the English language department at the Faculty of Letters and Human Sciences, Mohammed V- Agdal in Rabat was randomly selected. These participants, who took the university pre-entrance exam prior to admission, conduct their English Studies at the first-semester level in the same class. They are made up of mixed-ability learners and they are not repeaters. In addition, they have a compatible academic background. The selection of EFL first-semester students is grounded in the premise that at this academic stage (Semester One), learners' (meta) cognitive reading strategy awareness and use are presumed to be typically inadequate. This will further highlight useful implications in the teaching of EFL reading within the Moroccan university setting.

\subsection{Procedure}

Predicated on an exploratory research design, this study taps two typologies of reading comprehension texts (narrative and expository) and a retrospective questionnaire. Actually, the reading texts were assigned to the target group for a two-hour period. The reading texts include four major reading tasks: the wh-question task, the meaning-inferring task, the paraphrasing 
task, and the summarizing task. The performance of these reading-oriented tasks implies that the participants resort to the perceived use of cognitive as well as metacognitive strategic moves.

The first task is made up of five wh-questions which required the participants to process the written texts under study entirely so as to provide correct, valid responses. In effect, unlike true/false questions which tend to allow readers to depend on random guessing (Nara \& Noda, 2003), wh-questions entail that learners use a wide host of text-processing strategies. In the second task, the EFL learners under focus were expected to opt for the convenient, equivalent concept. Four terminologies, which are overtly stated by the writer/author in the reading passages, were presented. This implies that the participating learners had to use their inferential abilities and cognitive processes to understand the connotation of the target concepts. Concerning the third task, it is primarily associated with the paraphrasing process. The learners were supposed to read three statements and rephrase them in their own words. This can reflect the learners' awareness of the techniques used in paraphrasing. With reference to the last task, it is closely interrelated with the evaluating strategy of summarization. At this stage, the target learners were asked to write a fairly short summary of each reading passage (narrative and expository).

This reading task was accompanied by a retrospective questionnaire (RQ) so as to delve deeply into the target learners' cognitive and metacognitive reading strategy awareness and usage. Whilst the 'think-aloud protocol entails that learners report on their evoked strategies used in coping with the written discourse in a simultaneous fashion (Bereiter \& Bird,1985), the retrospective questionnaire (RQ) can be completed shortly after finishing the operation of textual analysis and synthesis. This allows for the subjects to be fully involved in the conceptual act of reading, and thus declaring the major cognitive and metacognitive strategic moves invoked for the construction of the understanding of the inherent content.

The rationale for the reliance on this type of questionnaire was to obtain deeper knowledge of whether the target participants use the cognitive and metacognitive strategies consciously or unconsciously. Unlike other forms of questionnaires which, at times, explore only the findings of quantitative type, the RQ depended upon for the methodical conduct of this current case study is of both quantitative and qualitative nature. In effect, many different questions are included to tap into rich, persuasive data that can be relevant to the set research questions. This process of mixing various types of questions in the questionnaire does have the potential of undertaking an effective investigation.

The main 'constructs' to be measured in this study are the cognitive and metacognitive reading 'heuristics'. They are, indeed, deemed the core variables that are under critical investigation. Thus, the efficient data collection medium used was the RQ whose significant goal is the delineation of whether the target groups are conscious or unconscious of these types of strategies while being involved in their reading of written texts. It was systematically constructed by incorporating almost all the questions and items which ultimately embody the investigated types of RSs (cognitive and metacognitive). This was accomplished to assure adequate, clear-cut responses from the EFL subjects. 


\section{Ml Macrothink}

Before starting the act of gathering the data, it was imperative that the efficient feasibility of the instruments be warranted. Recourse to the process of 'piloting' the data collection tools was made in order to pinpoint some inadequacies at the level of the content. Two reading texts (narrative and expository) and a RQ were administered to a small group of 10 university students. This acquainted the researcher with the fact that the included comprehension questions were clear and the time allocated to the reading process was fairly sufficient. Therefore, some slight alterations were made to improve, in a way, the quality of the reading comprehension texts and to make sure that the probing questions relating to strategy awareness and application in the RQ were predicated on precision and clarity.

The data obtained by means of the RQ were computed through the Excel software Program (version 2007) with a view to setting forth an accurate measurement of the frequent (meta) cognitive strategies of which the target group is aware. This was numerically counted in percentile forms and illustrative figures are used to reflect insights into the participating EFL learners' reading strategy consciousness and usage. The frequency counting and proportions of strategy awareness and use were depended upon in order to account for the set research goal.

\section{Findings}

\subsection{EFL Learners' Awareness of Cognitive \& Metacognitive Text-processing Strategies}

It is clear that only a small number of the subjects targeted in this study seemed to be aware of some cognitive and metacognitive reading strategies (RSs) that are implemented in EFL textual reading. This showcases that the target EFL learners do not possess fairly large knowledge regarding the cognitive and metacognitive techniques that can be used in the reading of different written texts (e.g., narrative, expository). The findings pertaining to this stated fact are illustrated in the following figure.

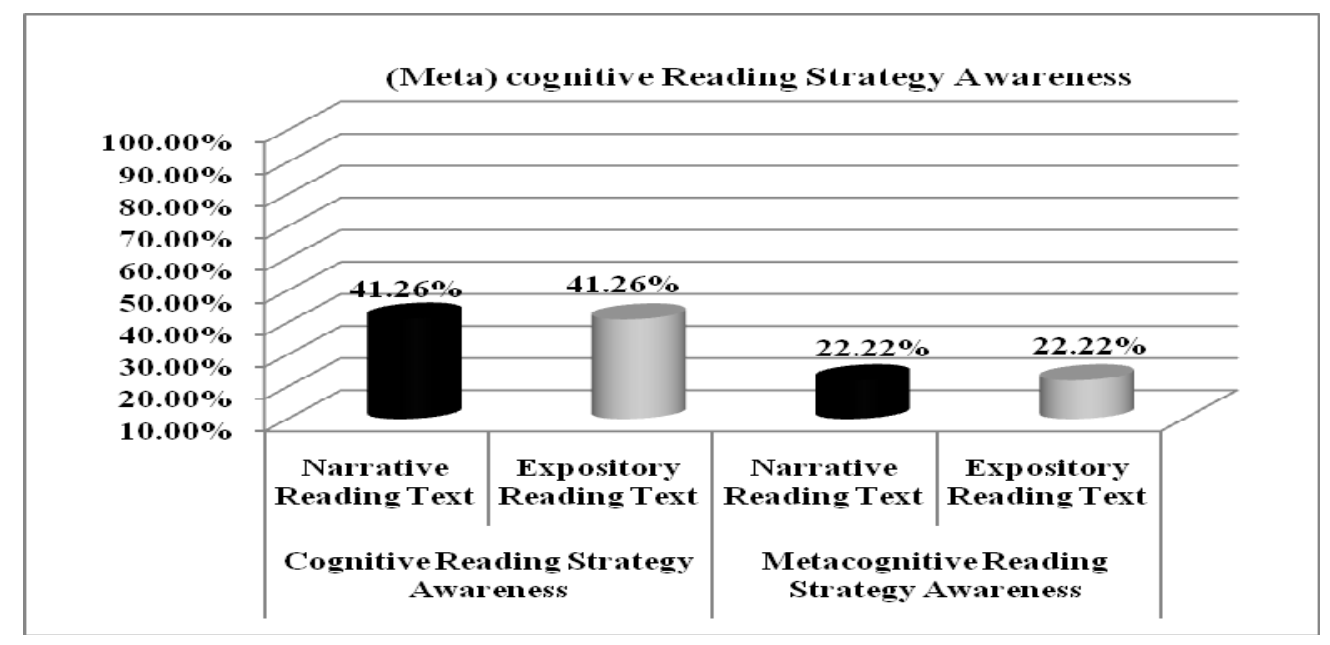

Figure 1. EFL Learners' Awareness of Cognitive \& Metacognitive Reading Strategies

As the data above demonstrate, seemingly insufficient awareness of cognitive reading strategies (CRSs) and metacognitive reading strategies (MRSs) is an undeniable fact among 


\section{Macrothink}

International Journal of Learning and Development

ISSN 2164-4063

2020, Vol. 10, No. 2

the targeted EFL group. Indeed, the majority of the subjects did not have wider knowledge of these reading 'heuristics' that can be applicable to any given written discourse. Obviously, the CRSs which some of the participants in the group were aware of are represented with a percentage of $41.26 \%$ for both the narrative and expository reading texts. Further, their awareness of MRSs was reflected with an even frequency of $22.22 \%$ for both types of written texts (i.e., narrative, expository).

According to the retrospective data, most EFL learners addressed in this study did not reveal full, deep consciousness of metacognitive text-related strategies. It can be stated that, though most of the participating EFL learners were not aware of this particular kind of reading techniques, some strategic moves such as background knowledge use, self-monitoring, and rereading, which are metacognitive in nature, were unconsciously executed by them in their cognitive endeavor to approach the assigned textual input (e.g., narrative, expository) (see Figure 2). This shows that EFL learners, at times, automatically deploy some, but not all, MRSs of which they lack adequate awareness.

\subsection{EFL Learners' Usage of Cognitive \& Metacognitive Text-processing Strategies}

Similar to the case of cognitive and metacognitive reading strategy awareness, it is plain that the targeted group revealed a tendency towards the use of more cognitive than metacognitive reading strategies (RSs) while being involved in the act of text reading (i.e., narrative, expository). This is unveiled in the ensuing Figure and table.

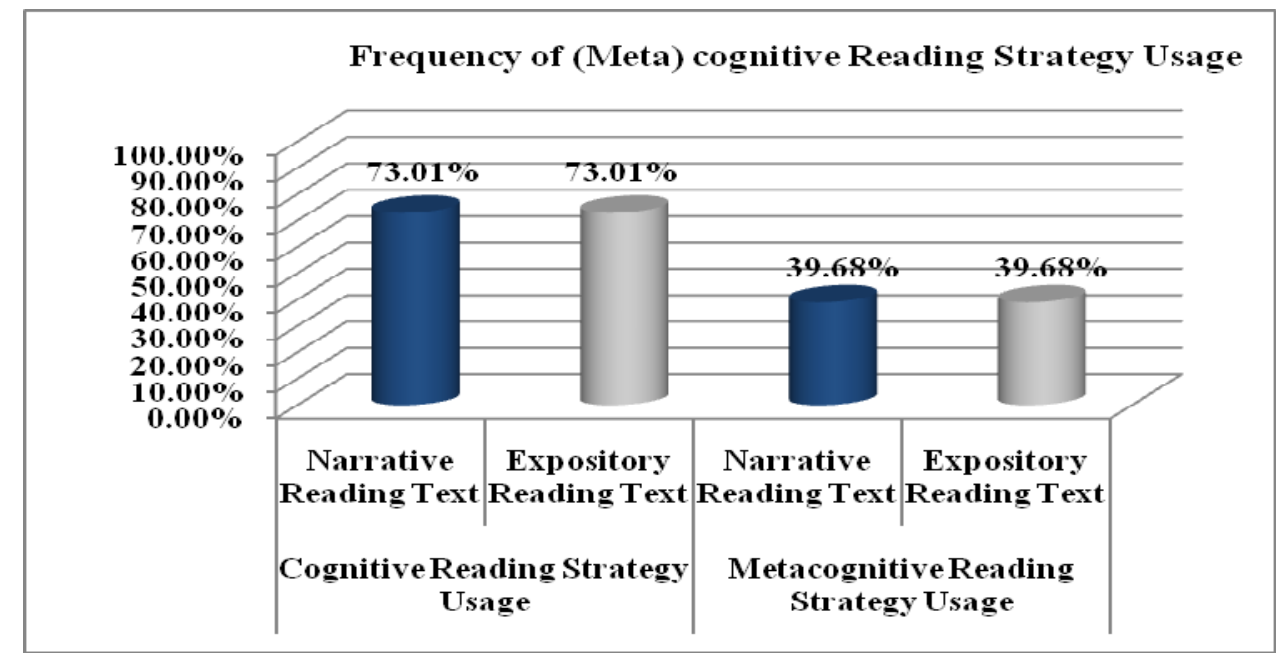

Figure2. EFL Learners' Usage of Cognitive \& Metacognitive Reading Strategies 


\section{Macrothink}

Table 1. EFL Learners' Awareness and Usage of Cognitive \& Metacognitive Reading Strategies

\begin{tabular}{|c|c|c|c|c|c|}
\hline \multirow[b]{2}{*}{ Reading Text } & & \multicolumn{4}{|c|}{ Respondents $(\mathrm{N}=63)$} \\
\hline & & $\begin{array}{c}\text { Cognitive } \\
\text { Strategy } \\
\text { Awareness }\end{array}$ & $\begin{array}{c}\text { Metacognitive } \\
\text { Strategy } \\
\text { Awareness }\end{array}$ & $\begin{array}{c}\text { Cognitive } \\
\text { Strategy } \\
\text { Usage }\end{array}$ & $\begin{array}{l}\text { Metacognitive } \\
\text { Strategy Usage }\end{array}$ \\
\hline \multirow{2}{*}{ Narrative } & $\mathrm{N}$ & 26 & 14 & 46 & 25 \\
\hline & $\%$ & $41.26 \%$ & $22.22 \%$ & $73.01 \%$ & $39.68 \%$ \\
\hline \multirow{2}{*}{ Expository } & $\mathrm{N}$ & 26 & 14 & 46 & 25 \\
\hline & $\%$ & $41.26 \%$ & $22.22 \%$ & $73.01 \%$ & $39.68 \%$ \\
\hline
\end{tabular}

In comparing the cognitive and metacognitive RSs used by the participants throughout the reading process, one can observe that the target EFL readers reported employing more cognitive than metacognitive strategies in reading narrative and expository written texts. By taking a glance at the stated results, it is evident that the EFL group under focus reflected a heavy dependence on CRSs with a percentage of $73.01 \%$ for the narrative as well as the expository text, whereas MRSs were employed with a frequency of only $39.68 \%$ in reading both types of written texts (narrative and expository).

A thorough analysis of the views put forth in the RQ displays that though EFL learners implement more cognitive than metacognitive strategies in text processing, they seem to be unaware of the nature of these 'heuristic' processes as a wide repertory of cognitive reading strategies (CRSs) were used by the sampled subjects in an automatic way without being fully conscious, at times, of their strategic behavior during text reading. Further, metacognitive reading strategies (MRSs), which require 'higher-order' thinking skills and reasoning abilities, were not adequately employed by the target group. This reveals that heightened awareness of (meta) cognitive text-processing strategies can enable EFL learners to utilize them deliberately and consciously in analyzing the textual input.

\section{Discussion}

The current study's overall inquiry was oriented towards the exploration of Moroccan English department students' awareness and usage of cognitive and metacognitive reading strategies (RSs) in an academic educational setting. This stated goal served as a signpost for the conduct of this case study.

Based on the findings, it is evident that a number of the target EFL learners are, to some extent, 
aware of the cognitive reading strategies (CRSs) implemented in textual analysis. In more specific terms, the subjects sampled in this study did report their awareness and use of a range of cognitively-directed strategies (e.g., predicting, inferring, paraphrasing). In effect, their way of strategizing the written texts (narrative and expository) seemed to be dominated by the utilization of the cognitive 'heuristics'. Thus, it is posited that the targeted EFL learners' comprehension of the assigned texts can be predicated on the application of the cognitive strategic moves (Tabataba'ian \& Zabihi, 2011; Abou Shihab, 2011).

What is remarkably noteworthy is that, though the sampled EFL subjects stated that they relied on the cognitive strategic techniques (See Table 1), their awareness of these strategic moves is highly inadequate. This features that most of the participants made use of this type of strategies without being conscious of their nature. This established fact supports Baker and Brown's claim (1984) that readers, at times, make use of some strategies that they are not aware of in their reading of the text. One possible explanation for this postulate is that, due to the extensive, regular practice of certain cognitive reading strategies while processing the textual input, the learners' awareness of these strategies is reduced to a lower level. Thus, the usage of some, if not most, of the CRSs by the EFL learners is conducted in a somewhat automatic, unconscious manner.

The drawn conclusion regarding the cognitive strategy awareness is that, in their endeavor to unravel the text content, the target learners implemented some RSs intentionally and invoked others unconsciously. For instance, it is claimed that predicting, inferring, and visualizing the textual meaning can be undertaken by the learners with minimum awareness since these strategic steps do not require a great deal of 'self-control' and 'self-regulation'. This stated postulate is in complete concert with Davies's (1995) conception that strategies are consciously or unconsciously used by learners in their approaching and extending the meaning embedded within the confines of the written discourse. In addition, it can be declared that awareness of certain strategies does not always translate into actual use of the strategies concerned as Mokhtari and Sheory (2002) claim. Simply put, in spite of the fact that the subjects retrospectively reported the use of some strategies, they do not apply them more effectively in the reading process.

With respect to metacognitive reading strategies (MRSs), it is manifest that the overwhelming majority of the EFL subjects under focal study did not seem to be sufficiently aware of this sort of strategies. This is in accord with previous related research (Tavacoli, 2014; Ostovar-Namaghi \& Noghabi, 2014) claiming that the perceived use of MRSs is lacking among learners. Obviously, the awareness and use of the cognitive reading strategies (CRSs) were significantly predominant during the act of text processing among the sampled subjects. This is indicative of the premise that, due to the lack of awareness of some MRSs, the latter were underused throughout the course of textual analysis and synthesis among the target group.

The EFL learners' inadequate knowledge of (meta) cognitive reading 'heuristics' reveals that their cognitive attempts are directed towards comprehending the text in a spontaneous way. Their full awareness of the strategies that ensure an effective comprehensibility is not significantly sufficient. Accordingly, it can be stated that the degree of consciousness of some, 
if not all, the underlying (meta) cognitive RSs can increase the usage of these strategies in understanding the textual input amongst the EFL learners. This can be in support of the view that the learners' assumed knowledge as to what strategies to use during the reading act can consolidate strategy use in processing the text and, thus reaching thorough comprehension. This posited notion is advocated by Carrell (1989) who maintains that 'knowing that' precedes 'knowing how' (p.122). Put simply, Carrell (1989) intends to put forth that the variable of 'declarative knowledge' can be a basis for both 'procedural knowledge' and 'conditional knowledge' as far as text-processing techniques are concerned.

Therefore, the claim postulated in the first research hypothesis related to the fact that EFL learners are not sufficiently aware of cognitive and metacognitive RSs is justifiably validated. It can be put forward that the majority of EFL learners targeted in this study are not adequately conscious of these strategies that aid in the comprehension process. Clearly, their (meta) cognitive strategy usage seems to be somewhat higher than their (meta) cognitive strategy awareness since they tend to unconsciously employ some cognitive and metacognitive strategies of which they are not aware while processing textual input.

As to the second research hypothesis, it is partially confirmed as the target learners tended to use more cognitive than metacognitive RSs. Basically, the learners' usage of these typologies of RSs is characterized by inadequacy. In effect, their use of the MRSs (e.g., planning, monitoring, evaluating) is limited as long as they did not sufficiently use them throughout the reading process. This reveals that most of EFL learners do not depend on all the MRSs in the act of synthesizing the textual content. Overall, the contradiction resides in the fact that most participating EFL learners are not conscious of some cognitive and metacognitive RSs (e.g., predicting, inferring, underlining, rereading) that they 'unintentionally' use on a regular basis. Hence, not being aware of some strategies does not mean that the EFL readers do not make use of them in attempting to derive the meaning from the text (Baker \& Brown, 1984).

\section{Conclusion}

This study launched an inquiry into measuring Moroccan EFL learners' reading strategy awareness and usage from a metacognitive perspective. The findings showcased that the learners' awareness and deployment of MRSs are prototypically characterized by a certain measure of limitation. One likely valid explanation is that most of the participating EFL learners tended to process the written texts (narrative and expository) with little, if any, consciousness of the MRSs. Nevertheless, some reading strategies (RSs) were unconsciously implemented by a great number of the participating EFL learners. Thus, it is assumed that perceived awareness and use of MRSs remain inadequate among EFL learners.

It is of note to claim that the majority of the sampled EFL learners reflected a measurable amount of 'automaticity' in their use of some CRSs as well as MRSs. They oftentimes put into action the RSs of which they are not fully aware. This leads to the ultimate view that the usage of the reading techniques among the EFL learners does not mean that they have strong knowledge of them. This can be traceable to their accumulated experience in reading the EFL texts and other texts written in Arabic (L1) or French (L2). Nevertheless, the strengthening of the learners' perception as to 'what', 'how', 'when' and 'why' to use RSs can be achieved by 
means of the reading strategy instruction (Mokhtari \& Reichard, 2002; Rupley, et al., 2009). This can have a seemingly fruitful impact on the EFL learners' sense of reasoning and critical thinking in their way of constructing the text meaning.

In general, strategy awareness can contribute to enabling EFL learners to undertake an efficiency-bound kind of reading. It can also allow for exercising a sophisticated kind of 'self-control' and 'self-regulation' while tending to utilize the previously 'automated' strategies during reading the written materials. Thus, the promotion of strategic processing of the text content can be closely intertwined with the development of strategy knowledge as a platform for the effectual strategy deployment.

\section{Implications}

In light of the results, it is implied that strategy use can be executed on the basis of strategy awareness by the learners. However, some, if not all, of the participating EFL learners implemented some (meta) cognitive strategies though they were unaware of their essence. In fact, it is clear that the majority of EFL learners do not possess perceived awareness of (meta) cognitive RSs. This shows that the consolidation of reading strategy awareness among learners with a view to helping them apply effective RSs is a key requirement. Hence, reading strategy instruction should be integrated in the syllabus at the university level. The plausible view is that, unless EFL learners are explicitly instructed in (meta) cognitive RSs, their awareness and usage of these strategic moves remain relatively inadequate and ineffective. Obviously, the competent use of RSs can be deemed the outcome of the learners' heightened awareness of the differing strategies which can facilitate the construction of the text content.

\section{Limitations and Orientations for Future Research}

As it is reflected in the field of any academic research, the act of encountering limitations is a likely, undeniable fact. In this regard, the first limitation pertains to the notion of representativeness. It can be said that the undertaken study could have targeted a sizeable number of other English department learners belonging to different institutions within the Moroccan context. This could guarantee the generalizability of the findings. Hence, future research is to be oriented towards delving into reading strategy consciousness and usage by addressing a large sample size.

The second limitation of this study is incarnated in the process of drawing a comparison between two EFL groups of different levels. This involves either drawing a parallel between EFL first-semester learners and those studying in the fifth semester or juxtaposing first-semester EFL students with those of sixth semester in terms of (meta) cognitive strategy awareness and use. This would corroborate whether language proficiency is a gateway into being cognizant of (meta) cognitive strategies and their usage among EFL learners. This line of enquiry should be the research agenda of prospective research.

The third limitation relates to the research instruments tapped for the conduct of this study. Indeed, a myriad of methods relevant to data gathering could be used for ensuring the consistency and reliability of the reached findings. Granted that the retrospective questionnaire (RQ) was adopted for eliciting data on the EFL learners' (meta) cognitive reading strategy 
awareness and usage, it is recommended that future researchers resort to a corpus of data collection techniques (i.e., self-reports, interviews) for consistency purposes.

\section{References}

Abou Shihab, I. (2011). Reading as critical thinking. Canadian Center of Science and Education, 7(8), 209-218. https://doi.org/10.5539/ass.v7n8p209

Baker, L., \& Brown, A. L. (1984). Cognitive monitoring in reading. In J. Flood (Ed.), Understanding reading comprehension (pp. 21-44). Newark, DE: International Reading Association.

Bereiter, C., \& Bird, M. (1985). Use of thinking aloud in identification and teaching of reading comprehension strategies. Cognition and Instruction, 2(2), 131-156. https://doi.org/10.1207/s1532690xci0202_2

Boyraz, S. \& Altinsoy, E. (2017). Metacognitive awareness of reading strategies in EFL context. International Journal of Language Academy, 5(5), 159-167.

Carnoldi, C. (1990). Metacognitive control processes and memory deficits in poor comprehenders. Learning Disability Quarterly, 13(4), 245-255. https://doi.org/10.2307/1510351

Carrell, P. L. (1989). Metacognitive awareness and second language reading. The Modern Language Journal, 73(ii), 121-134. https://doi.org/10.1111/j.15404781.1989.tb02534.x

Corr, P. J. (2010). Automatic and controlled processes in behavioural control: Implications for personality psychology. European Journal of Personality, 24(5), 376-403. https://doi.org/10.1002/per.779

Davies, F. (1995). Introducing reading. London: Penguin Group.

Flavell, J. H. (1971). First discussant's comments: What is memory development the development of? Human Development, 14, 272-278. https://doi.org/10.1159/000271221

Flavell, J. H. (1976). Metacognitive aspects of problem solving. In Besnick (Ed.), The Nature of Intelligence (pp.231-235). Hillsdale, NJ: Erlbaum.

Flavell, J. H., Miller, P. H., \& Miller, S. A. (1993). Cognitive development. Englewood Cliffs, N.J: Prentice Hall.

Hartlage, S., Alloy, L. B., Vázquez, C., \& Dykman, B. (1993). Automatic and effortful processing in depression. The American Psychological Association, 113(2), 247-278. https://doi.org/10.1037/0033-2909.113.2.247

Hill, J. R., Hannafin, M. J. (1997). Cognitive strategies and learning from the world wide web. Educational Technology Research and Development 45(4), 37-64. https://doi.org/10.1007/BF02299682

Hong-Nam, K. (2014). ELL high school students' metacognitive awareness of reading strategy use and reading proficiency. The Electronic Journal for English as a Second 
Language, 18(1), 1-6. Retrieved from: www.tesl-ej.org/wordpress/issues/volume18/ ej69/ej69a4/

LaBerge, D., \& Samuels, S. J. (1974). Toward a theory of automatic information processing in reading. Cognitive Psychology, 6, 293-323. http://dx.doi.org/10.1016/0010-0285(74)90015-2

Lawrence, L. J. (2007). Cognitive and metacognitive reading strategies revisited: Implications for instruction. The Reading Matrix, 7(3), 55-71.

Levesque, C., Copeland, K. J., \& Sutcliffe, R. A. (2008). Conscious and nonconscious processes: Implications for self-determination theory. Canadian Psychology, 49(3), 218-224. https://doi.org/10.1037/a0012756

Lifshitz, M., Aubert Bonn, N., Fischer, A., Kashem, I. F., \& Raz, A. (2013). Using suggestion to modulate automatic processes: From Stroop to McGurk and beyond. Cortex: A Journal Devoted to the Study of the Nervous System and Behavior, 49(2), 463-473. https://doi.org/10.1016/j.cortex.2012.08.007

Mayer, R. E. (1996). Learners as information processors: Legacies and limitations of educational psychology's second metaphor. Educational Psychologist, 31(3/4), 151-161.

McFarland, D. J. (2017). How neuroscience can inform the study of individual differences in cognitive abilities. Reviews in the Neurosciences, 28(4), 343-362. https://doi.org/10.1515/revneuro-2016-0073

Mokhtari, K., \& Reichard, C. A. (2002). Assessing students' metacognitive awareness of reading strategies. Journal of Educational Psychology, 94(2), 249-259. https://doi.org/10.1037/0022-0663.94.2.249

Mokhtari, K., \& Sheory, R. (2002). Measuring ESL students' awareness of reading strategies. Journal of Developmental Education, 25 (3), 2-10.

Nara, H., \& Noda, M. (2003). Acts of reading: Exploring connections in pedagogy of Japanese. Honolulu: University of Hawai'i Press.

Ostovar-Namaghi, S. A., \& Noghabi, A. E. (2014). A comparison of perceived use of the metacognitive reading strategies by Iranian master of science students for hypertext and printed academic materials. Journal of Language Teaching and Research, 5(4), 865-872. https://doi:10.4304/j1tr.5.4.865-872

Pei, L. (2014). Does metacognitive strategy instruction indeed improve Chinese EFL learners' reading comprehension performance and metacognitive awareness? Journal of Language Teaching and Research, 5(5), 1147-1152. https://doi.org/10.4304/j1tr.5.5.1147-1152

Piccinini, G., \& Scarantino, A. (2010). Computation vs. information processing: Why their difference matters to cognitive science. Studies in History and Philosophy of Science, 41(3), 237-246. https://doi.org/10.1016/j.shpsa.2010.07.012

Rupley, W. M., Blair, T. R., \& Nicholas, W. D. (2009). Effective reading instruction for struggling readers: The role of direct/explicit teaching. Reading and Writing Quarterly, 
25(2/3), 125-138. https://doi.org/10.1080/10573560802683523

Schneider, W., \& Chein, J. M. (2003). Controlled \& automatic processing: Behavior, theory, and biological mechanisms. Cognitive Science, 27, 525-559. https://doi.org/10.1016/S0364-0213(03)00011-9

Schneider, W., \& Pressley, M. (1997). Memory development between 2 and 20. Hillsdale, NJ: Erlbaum.

Schraw, G. (1998). Promoting general metacognitive awareness. Instructional Science, 26 (1-2), 113-125. https://doi.org/10.1023/A:1003044231033

Shiffrin, R. M., \& Schneider, W. (1977). Controlled and automatic human information processing: II. Perceptual learning, automatic attending, and a general theory. Psychological Review, 84, 127-190. https://doi.org/10.1037/0033-295X.84.2.127

Solso, R. L. (1979). Cognitive psychology. New York: Harcourt Brace Javanovich, Inc.

Sternberg, R. J. (1984). Mechanisms of cognitive development: A componential approach. In R. J. Sternberg (Ed.), Mechanisms of cognitive development (pp.163-186). New York: W.H. Freeman and Company.

Tabataba'ian, M. S., \& Zabihi, R. (2011). Strategies used by four Iranian EFL learners in reading ESP and GPE texts: A think-aloud case study. World Journal of English Language, l(1), 53-62. https://doi.org/10.5430/wjel.v1n1p53

Takač, V. C. (2008). Vocabulary learning strategies and second language acquisition. Clevedon, Great Britain: Cromwell Press.

Taraban, R., Kerr, M., \& Rynearson, K. (2004). Analytic and pragmatic factors in college students' metacognitive reading strategies. Reading Psychology, 25, 67-81. https://doi.org/10.1080/02702710490435547

Tavakoli, H. (2014). The effectiveness of metacognitive strategy awareness in reading comprehension: The case of Iranian university EFL students. The Reading Matrix, 14(2), 314-336.

Vellutino, F. R. (2003). Individual differences as sources of variability in reading comprehension in elementary school children. In A.P. Sweet and C.E. Snow (Eds.), Rethinking reading comprehension (pp. 51-81). New York: The Guilford Press.

Walszyk, J. J. (2000). The interplay between automatic and controlled processes in reading. Reading Research Quarterly, 25 (2), 554-566.

Wood, G. (1983). Cognitive psychology: A skills approach. California: Cole Publishing Company.

Zhang, L. J., \& Wu, A. (2009). Chinese senior high school EFL students' metacognitive awareness and reading-strategy use. Reading in a Foreign Language, 21, 37-59. 


\section{Macrothink}

International Journal of Learning and Development

ISSN 2164-4063 2020, Vol. 10, No. 2

\section{Copyright Disclaimer}

Copyright for this article is retained by the author(s), with first publication rights granted to the journal.

This is an open-access article distributed under the terms and conditions of the Creative Commons Attribution license (http://creativecommons.org/licenses/by/4.0/). 